\title{
Article
}

\section{The influence of portfolio aims and structure on student attitudes towards portfolios as a learning tool: A Scoping Review}

Stewart, Heather Christine, Roddam, Hazel, Wisby, Deborah Ann and Selfe, James

Available at http://clok.uclan.ac.uk/17480/

Stewart, Heather Christine ORCID: 0000-0002-4657-3221, Roddam, Hazel ORCID: 0000-0002-0637-1801, Wisby, Deborah Ann and Selfe, James (2017) The influence of portfolio aims and structure on student attitudes towards portfolios as a learning tool: A Scoping Review. Physical Therapy Reviews, 22 (1-2). pp. 86-94. ISSN 1083-3196

It is advisable to refer to the publisher's version if you intend to cite from the work. http://dx.doi.org/10.1080/10833196.2017.1312844

For more information about UCLan's research in this area go to http://www.uclan.ac.uk/researchgroups/ and search for <name of research Group>.

For information about Research generally at UCLan please go to http://www.uclan.ac.uk/research/

All outputs in CLoK are protected by Intellectual Property Rights law, including Copyright law. Copyright, IPR and Moral Rights for the works on this site are retained by the individual authors and/or other copyright owners. Terms and conditions for use of this material are defined in the policies page. 
1 The influence of portfolio aims and structure on student attitudes towards portfolios as

2 a learning tool: A Scoping Review.

3

4 Heather Stewart, School of Health Sciences, University of Central Lancashire, Preston, UK

5 Dr. Hazel Roddam, School of Health Sciences, University of Central Lancashire, Preston,

6 UK

7 Dr. Deborah Wisby, College of Health and Wellbeing, University of Central Lancashire,

8 Preston, UK.

9 Professor James Selfe, Faculty of Health, Psychology and Social Care, Manchester

10 Metropolitan University, Manchester, UK

11 


\section{Abstract.}

13 Background: Portfolios are widely used in undergraduate health professional education, however the majority of literature suggests that these are poorly received by students, in terms of being an effective learning tool. Objectives: to evaluate whether the aims/purpose or structure/level of standardisation/content of student portfolios influences their attitudes to and perceptions of its use as a learning tool. Major Findings: Aims/purpose and structure/level of standardisation/content of portfolios were analysed in relation to student responses in order to determine any relationship between these. The level of information provided in the studies was variable, making analysis difficult, however there appeared to be no clear link between any of these factors and student responses. The interplay of level of support and guidance, the time required for completion of the portfolio, and the role of assessment appear to have the greatest influence on student views.

Conclusions: Considering the wide use of portfolios in health professional education, student support for these is limited, and further research is required to determine if alternative approaches to portfolio learning can positively influence student attitudes and perceptions. Key Words: portfolio; professional education; student; attitude and perceptions; influence on learning 
Introduction.

The evidence for the use of portfolios within education began to appear in the 1990's, in teacher education, ${ }^{1}$ the arts, ${ }^{2}$ nursing, ${ }^{3}$ and medical education. ${ }^{4}$ The first published evaluation of portfolio use in Physiotherapy education was in $1997 . .^{5}$ There are many varied definitions of a portfolio, ${ }^{6-9}$ with two clear types of portfolios identified - that of the portfolio as a tool to demonstrate achievement, or a best work portfolio, ${ }^{10-13}$ and the portfolio that is used to aid progress and growth, or a learning portfolio. ${ }^{11,14-15}$

The reported key benefits of a portfolio within healthcare education, are that it encourages personal reflection on experiences, learning and development, ${ }^{16}$ provides a useful link between academic knowledge and clinical practice, ${ }^{17}$ makes students more aware of their own learning, ${ }^{18}$ and promotes critical thinking. ${ }^{19}$ Portfolios should also encourage students to develop the abilities they will need to become independent and self-directed learners. ${ }^{20}$ Personal experience of using portfolios over many years and in different formats with undergraduate Physiotherapy students, suggested that despite the reported benefits listed above, students did not perceive the portfolio to be useful, or to value its completion. A relatively recent portfolio model by Zubizarretta (2008) suggests that three key components need to be included in portfolio development, if students are to learn at a deep level through their use (see Figure 1). ${ }^{21}$ The first component is the inclusion of evidence, followed secondly by the process of reflection, which has been noted to be critical to the success of learning through use of a portfolio. ${ }^{22,23}$ Finally, the inclusion of collaboration recognises that although professional development is the responsibility of the individual, students beginning this process need guidance, feedback and advice from more skilled and knowledgeable professionals, ${ }^{21}$ and it is suggested that this process of mentoring is the most decisive factor in portfolio success. ${ }^{24}$ 


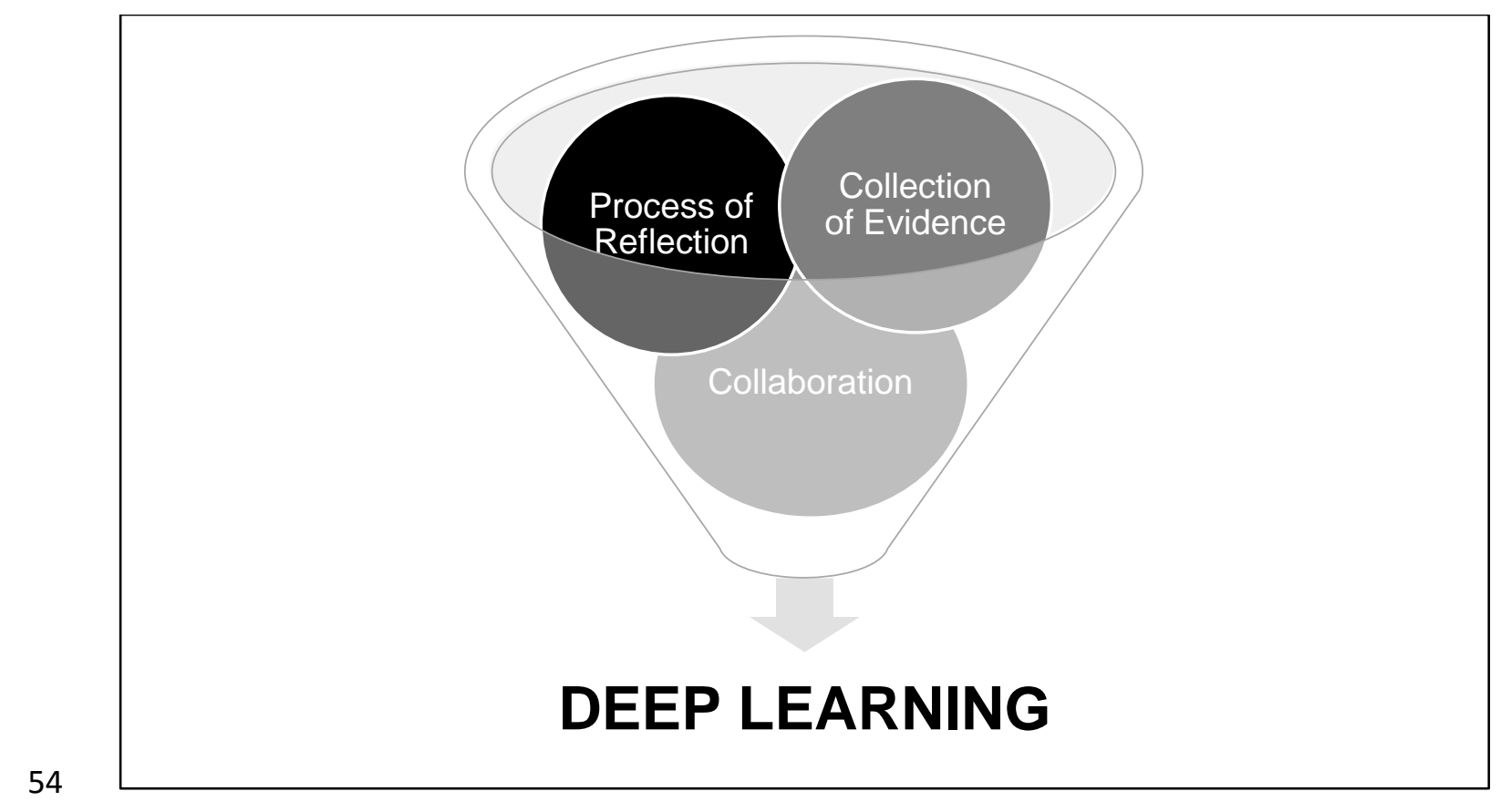

Figure 1. Diagrammatic Representation of Zubizarretta (2008) ${ }^{16}$ Model of Portfolio Learning.

In order to consolidate the knowledge and research findings on the use of portfolios in undergraduate health education, as well as to identify gaps within the research, a scoping review was undertaken as part of a course of study at doctoral level. The doctoral review aimed to investigate factors influencing student perceptions of and attitudes to use of undergraduate portfolios in the broadest context. In order to focus the findings for this publication, findings from the review will be discussed in relation to the following two questions -

1. Do the aims/purpose of the portfolio influence the students' perceptions of and attitudes towards portfolio use?

2. Does the structure/format or required content influence the students' perceptions of 
Methods.

71 As this research is a scoping review, ethical approval was not sought. Literature searches took

72 place between $10^{\text {th }}$ September and $6^{\text {th }}$ October 2014, using 12 databases (see Table 1); each

73 was searched from the oldest issue available up to August 2014.

74 Table 1. Databases searched.

DATABASES SEARCHED

Academic Search Complete

Amed

Biomed Central

British Education Index

Cinahl complete

Embase

Maternity and Infant Care

Medline

ProQuest Hospital Collection

PsychArticles/PsychInfo

Science Direct

Sports Discus

75

Search terms were identified through previous background reading, and were categorised into four themes. Both continuing professional development and its abbreviation, CPD, were included as search terms, in order to broaden the findings from the literature search. Search terms were combined using the Boolean operator AND (see Table 2), and where possible, searches were performed within Title, Abstract, or Keywords to limit the number of hits and improve relevance of results. 
Table 2. Search terms and search combinations.

\begin{tabular}{|l|l|l|l|}
\hline $\begin{array}{l}\text { THEME 1 - } \\
\text { Portfolio }\end{array}$ & THEME 2 - Student & $\begin{array}{l}\text { THEME 3 - } \\
\text { Learning }\end{array}$ & THEME 4 - Attitude \\
\hline Portfolio & Student & $\begin{array}{l}\text { Continuing } \\
\text { Professional } \\
\text { Development }\end{array}$ & Perception \\
\hline & Undergraduate & CPD & Attitude \\
\hline & & Lifelong Learning & Preferences \\
\hline & & & Views \\
\hline & & & Behaviours \\
\hline & & Evaluation \\
\hline & & Purpose \\
\hline Theme 1 AND Theme 2 & \\
\hline Theme 1 AND Theme 3 & & \\
\hline Theme 1 AND Theme 4 & & \\
\hline Theme 1 AND Theme 2 AND Theme 4 \\
\hline
\end{tabular}

83

Articles retrieved had to be published in the English Language and provide data on student perceptions or attitudes towards use of a portfolio to be included in the review. Hand searching of references lists also produced some included papers.

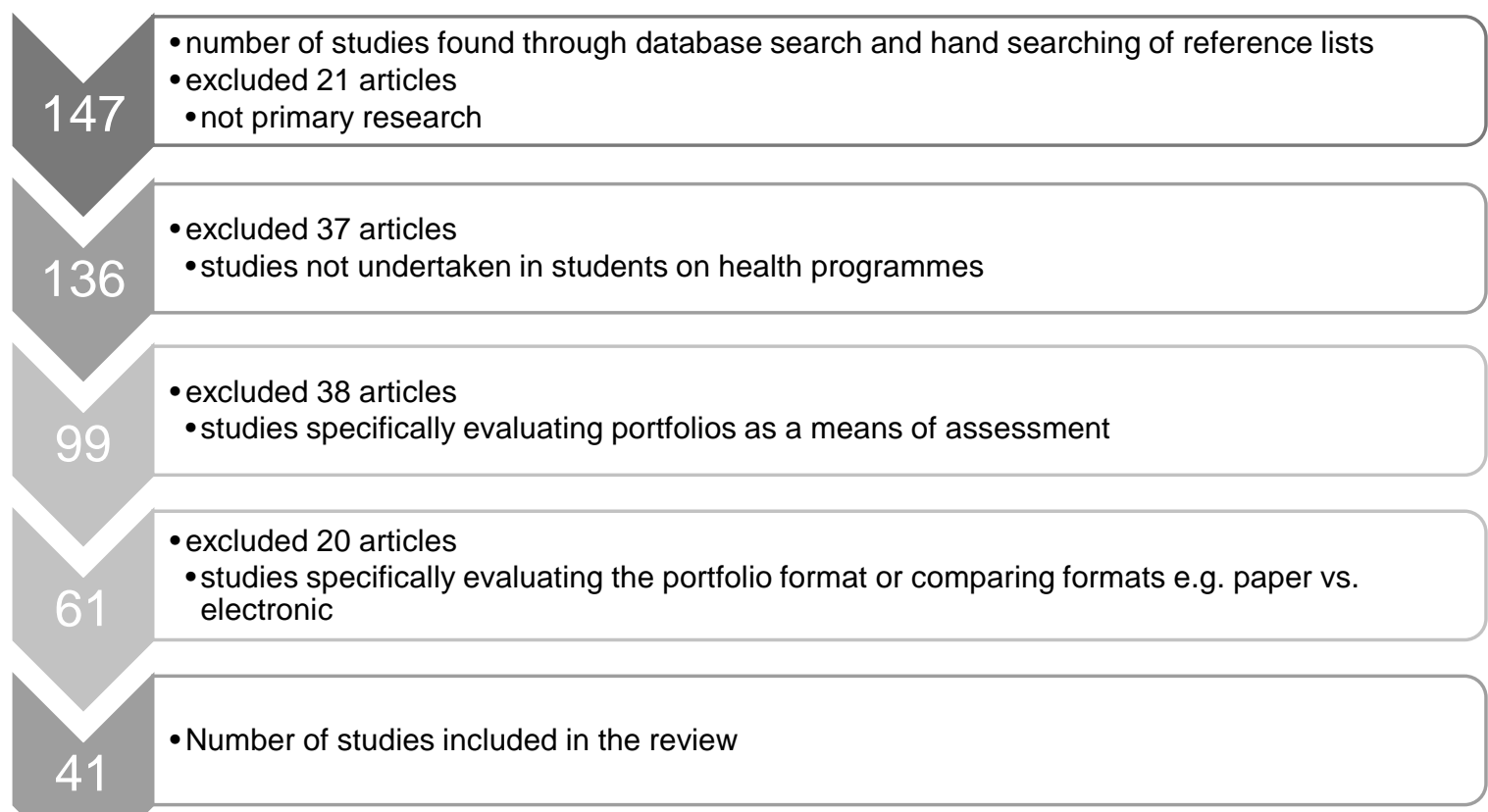

\section{Figure 2. Literature search process.}


The initial sample included 147 scientific articles, editorials, commentaries, and opinion pieces. Papers were excluded from this sample using the criteria outlined in the flowchart in Figure 2. The final sample included in the review was 41.

\section{Analysis of Literature}

One author analysed the research, as this was undertaken as part of a programme of doctoral study, however the analysis was discussed with all authors as part of the supervisory process. On initial reading of the research studies, the first author became familiar with the key ideas and recurrent topics being raised, either from the qualitative comments made by student participants during interviews or focus groups, or from the questions asked and responded to in questionnaires. Following a process of qualitative data analysis as described by Bryman and Burgess (1994) $)^{25}$, these key ideas and topics were then developed into a theoretical framework (see Figure 3), which was discussed and finalised by all authors. Indexing and charting of the empirical data then took place in relation to this framework, with the reported data from each individual study charted as either positive or negative in relation to the student's perception of each the topics identified in Figure 3. These results were then mapped against the identified possible influencing factors - portfolio aims/purpose (see Appendix 1); level of standardisation of the portfolio (see Appendix 2); the basis or format of the portfolio; portfolio content - and findings interpreted to draw conclusions.

\section{Results.}

\section{Description of the sample.}

Of the 41 studies reviewed, 40 were published in peer-reviewed journals, between 1994 and 2014, with the majority published between 2003 and 2012. One study was a thesis, from the 


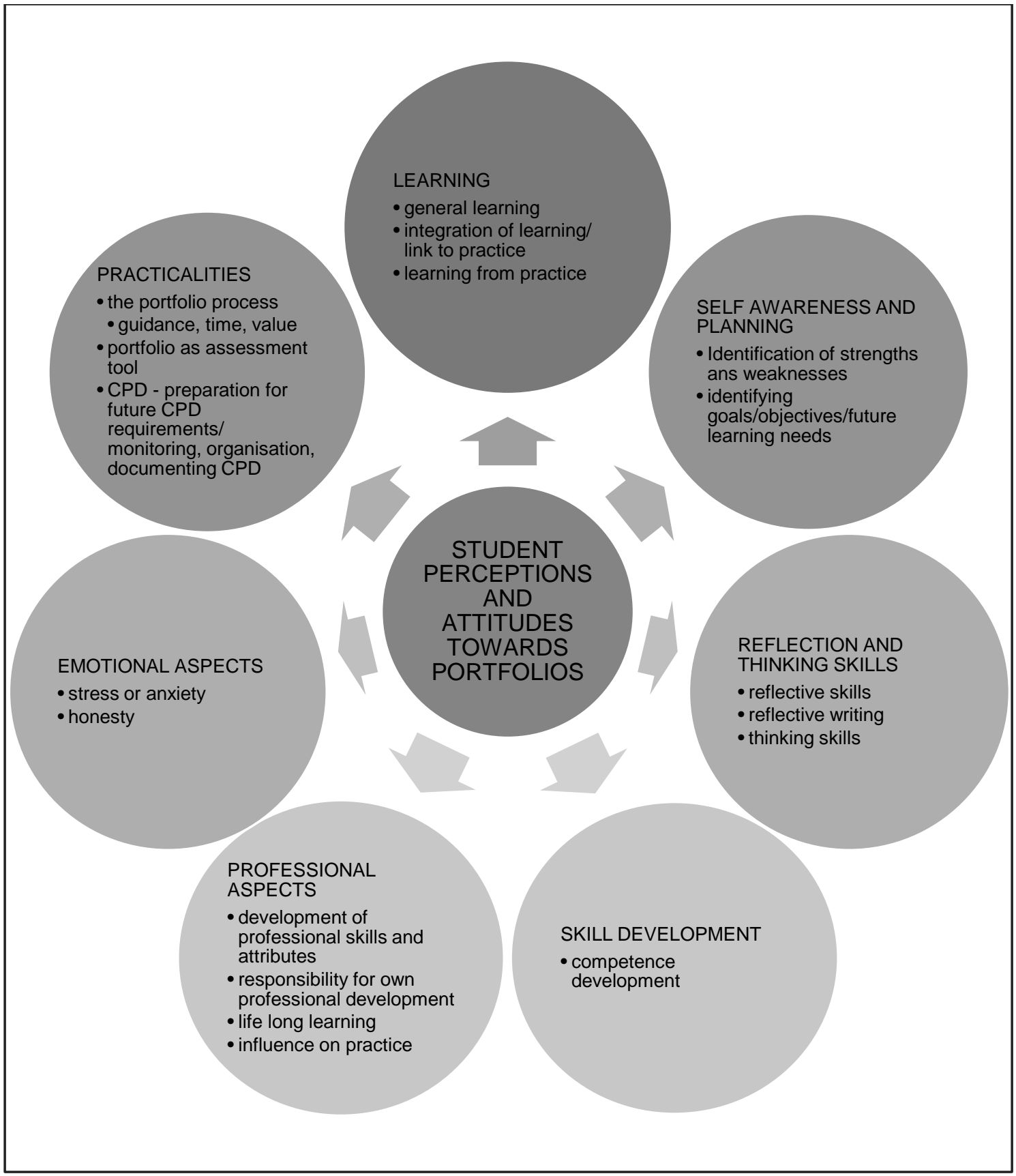

Figure 3. Themes emerging from analysis of qualitative and quantitative data.

116 University of Iowa. ${ }^{26}$ The research was undertaken mainly in the Western world (United

117 Kingdom (UK) n=16; United States of America (USA) n=10; Europe n=8; Australia and New

118 Zealand $n=3$; Canada $n=2$;) with only one study from Africa, ${ }^{27}$ and one study from the Far

119 East. $^{28}$ Distribution of research by profession is shown in Figure 4. 


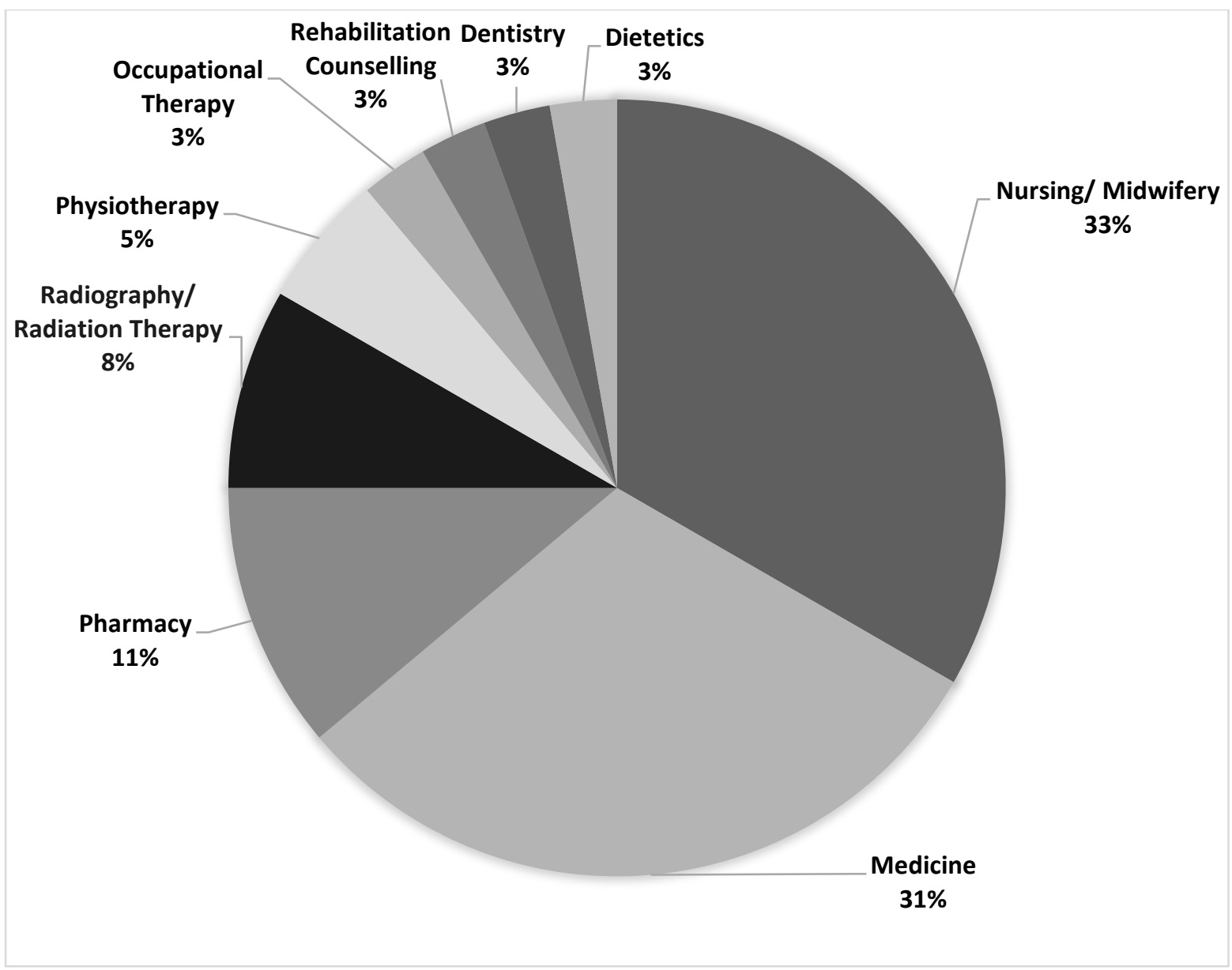

\section{Figure 4 - Distribution of research from different professional groups.}

122 This review included studies with a range of data collection methods. Twenty-four studies used a questionnaire; some of these were postal, or students completed them in a classroom and some were completed electronically. Four studies used interviews and four had a mixed methodology (e.g. a combination of questionnaire and interview, or questionnaire and focus groups). Three studies analysed the content of the student portfolios as their data collection method, while focus groups, discussion groups, outcome measures, or presentation and sharing were each used in one study. Data collection method was unclear in two studies.

Detail regarding the subjects of the studies was limited, with three of the 41 studies provided no information about their student sample. ${ }^{31,43,50} 34$ of the 41 studies provided sample sizes, ranging from four ${ }^{39}$ to $413 .{ }^{44}$ Only three studies ${ }^{32,33,48}$ provided information regarding the age 
133 Twelve studies provided data regarding the ratio of male to female participants; in all cases, 134 studies had a greater proportion of female subjects. In terms of the stage of study, there was significant variation, and with 11 studies giving detail. Four studies recruited first year students, ${ }^{33,34,40,45}$ three studies included students from across different years of the course, ${ }^{28,}$ 32, 38 two studies used students who were partway through their course, ${ }^{36,46}$ one included only final year students, ${ }^{51}$ and one study’s participants had recently completed their course. ${ }^{48}$

\section{Aims/purpose of the portfolios.}

Only 18 of the 41 studies provided information regarding the aims or purpose of their student portfolio. These fell into six categories - a collection of evidence, ${ }^{29-35}$ a means of developing reflective skills, ${ }^{27,}$ 30, 33-36 to develop self-awareness and professional identity, ${ }^{30-31,37-38}$ for the purpose of assessment, ${ }^{30-32,36,38-41}$ a communication tool, ${ }^{32,35,38,42-43}$ and to develop students' learning processes. ${ }^{30-32,35,38,42,44}$ Overall there was a lack of standardisation of the aims across the portfolios described, and a number of studies’ portfolios had more than one aim.

\section{Structure, format and content of the portfolios.}

The research found generally lacked detail in terms of the structure, format or level of standardisation of their student portfolios. 16 of the 41 studies gave some indication of whether their portfolio was of a standardised structure, semi-standardised or completely flexible. Two early studies, one in Physiotherapy, ${ }^{5}$ and one in medicine, ${ }^{29}$ presented portfolios at opposite ends of the standardisation spectrum, with one providing a rigid structure ${ }^{5}$ and the other no standardised structure at all. ${ }^{29}$ More recent studies described portfolios that have reached a semi-standardised compromise, providing some overarching structure in terms of the expectations of the portfolio (for example providing section headings or guidance re

157 formatting), while allowing students flexibility about what evidence they collect, or how this 
is used to demonstrate achievement of requirements. Eight studies based their portfolio structure on professional standards or competency frameworks, 5, 31-32, 36, 39, 45-47 three around programme or module learning outcomes, ${ }^{40-41,44}$ and two around theoretical frameworks of learning. ${ }^{35,43}$

The content of the student portfolios varied widely, with 25 of the 41 studies giving information about content. As part of this review, content was grouped into seven broad categories - ethical issues and dilemmas, ${ }^{28,} 40,43$ reflective elements, 5, 31-33, 36, 38, 40, 43-44, 47-49 academic components such as assignments or classroom notes, ${ }^{5,28-30,35,38-42,45,49}$ evidence of working with others, ${ }^{31, ~ 37, ~ 40, ~} 49$ checklists and documents, 5, 28-29, 32, 35-37, 42, 45, 47-49 patient/client related evidence, 5, 27-28, 30-32, 34-35, 37, 39-40, 42-44, 46, 49 and learning agreements and personal development plans. ${ }^{5,38,40,42-43,45-46,48}$ There is a lack of clarity as to whether elements categorised as working with others and patient/client experiences are students' reflections on these experiences or simply descriptive documents evidencing that this was done. Many of the studies described portfolios requiring content from more than one of these categories.

\section{Student perceptions and attitudes towards portfolios.}

All 41 studies provided either quantitative and/or qualitative data regarding students’ perceptions and attitudes towards the use of a portfolio. A range of data collection methods were used, with no specific method being favoured by authors from any one professional group.

\section{Discussion.}

Do the aims/purpose of the portfolio influence the students' perceptions of and attitudes towards portfolio use? 
Based on the data provided, it is difficult to draw any strong conclusions regarding any relationship between aims or purpose of the portfolios, and the students' perceptions of and attitudes towards use of a portfolio (see Appendix 1). In general terms, comments relating to the influence of the portfolio on practice, the emotional factors involved in the portfolio, the time taken to complete the work, the link between theory and practice, and the guidance given were negative, irrespective of the aim of the portfolio. The question regarding whether students saw any value to completion of a portfolio was wholly answered negatively across all aims. Interestingly, improvement in reflective skills was reported by the majority of students, and although students did not value their portfolios, they could see that it had prepared them for future practice regardless of its intended purpose.

Students whose portfolio aimed to specifically develop reflective skills, ${ }^{27,30-31,33-36}$ responded positively with regard to learning from practice, and the development of self-awareness, reflective skills and thinking skills. These students also appeared to have fewer concerns regarding the time taken to complete the portfolio.

Similarly, students whose portfolio aim was to meet assessment criteria, ${ }^{29,} 31-32,36,38-41$ also responded positively with regard to reflective and thinking skills, but also felt that the portfolio enabled them to develop their professional skills and attributes, and a responsibility for their own learning. Students in this group of studies were concerned about the guidance given for portfolio completion more strongly than others, and this may have been because of the specific focus on assessment in the aims of the portfolio. These students also reported that they felt unable to be completely honest in the content of their portfolios due to it being assessed. Finally, there were mixed views from students whose portfolio aim was assessment, with regard to the portfolio as an assessment tool, compared with the majority of other studies, where the student opinion was mainly negative. 
Studies where collecting evidence was the aim generally found students reported less negatively than in studies with other aims. ${ }^{29-35}$ This is perhaps because the lack of requirement for critical thinking, analysis or reflection meant students did not find the task challenging. The overall lack of positive comments from student responders in these studies ${ }^{29-35}$ could also suggest that the students found the creation of their portfolio unstimulating.

Does the structure/format or required content influence the students' perceptions of and attitudes towards portfolio use?

As with the previous discussion, it is difficult to draw any strong conclusions regarding the relationship between structure, format or content and student responses to the studies (see Appendix 2). Across all formats (level of standardisation; basis, type of content required) of the portfolios described in the research, the general opinion of students was negative in terms of time requirements, level of guidance provided and the value of completing a portfolio.

Overall, semi-standardised formats received a higher proportion of positive comments, ${ }^{29,} 32,36$,

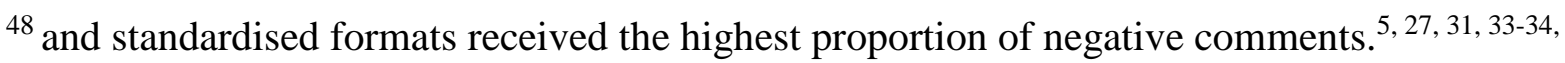
41-43, 47, 49-50 Semi-standardised portfolios that allowed some flexibility in terms of content or format appeared to encourage students to think more deeply, ${ }^{51}$ learn from practice, take

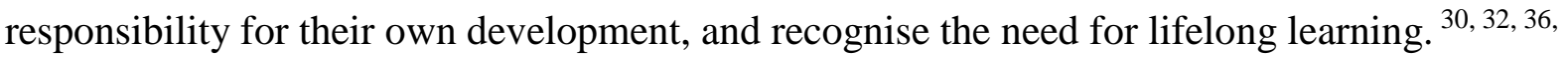
${ }^{48}$ Both standardised or semi-standardised formats did allow students to see that developing their portfolios had prepared them for future CPD requirements.

In terms of the basis for the portfolio, those based on professional standards, 5, 27, 32, 36,46 generated more positive responses to the themes than those based on either competency standards, ${ }^{39,45,47}$ learning outcomes, ${ }^{40-41,44}$ or theoretical concepts. ${ }^{35,43}$ When analysing the content of the portfolios against the students' views, similar themes arose, with no particular type of content showing specifically positive or negative comments. 
231 Across all the studies giving detail of content, students responded positively regarding development of reflective skills, taking responsibility for their own learning, understanding the role of lifelong learning, and being prepared for the future. Thinking skills received mainly positive responses.

Returning to the portfolio model as described by Zubizarretta (2008), several comments can be made. ${ }^{21}$ Firstly, by nature of the definition of a portfolio, all of the studies required the students to collect evidence, although it is not clear in all studies what this included, or whether there was any requirement for critical writing about the evidence collected. The findings from this review of the literature suggest that pure collection of evidence does not elicit strong feelings from students, either positively or negatively, suggesting perceived lack of achievement and lack of stimulation. Secondly, although the aims of only seven studies required the need for reflection, the majority of studies did in fact include this element, and students responded positively in all studies regarding the development of reflective skills. Thirdly, the findings with regard to collaboration are limited, and so it is difficult to draw firm conclusions about how student support in the portfolio-building process influences whether students value their portfolios or achieve deep learning from them. Students completing standardised portfolios felt restrained by having too much guidance, ${ }^{5}$ yet not enough guidance left students feeling confused about what was expected. ${ }^{33,35-36,41,44,49}$ It is also unclear whether, when answering questions about guidance, students are referring to face-to-face guidance, which would be considered collaboration or mentoring, ${ }^{21}$ or whether they are referring to written instruction on how to complete their portfolio. The challenge for educators appears to be creating a balance between enough guidance so that students feel empowered to undertake the task without stifling their creativity, ensuring all members of the course team involved in student support understand the process, the allowances for flexibility 
and definitive requirements, whilst also factoring in the need for objectivity and parity if the portfolio is to be assessed.

Considering the current drive by professional and statutory bodies to enforce CPD within qualified health professionals in both the UK and around the world, ${ }^{52-57}$ it is encouraging that students felt that using a portfolio prepared them for their future CPD requirements. However, this move to regulation of CPD may have influenced educators to design undergraduate portfolios that allow students to meet these requirements, to the detriment of developing as learners through reflecting on the experiences under the guidance of a more experienced practitioner.

Only one study, by Dolan et al (2004), described a portfolio whose aims incorporated all of these three elements, yet despite this, these UK-based student nurses' attitudes towards and perceptions of their portfolio remained largely negative ${ }^{35}$. While they responded positively regarding its use as a reflective tool, they did not value the portfolio and gave it a low priority, and $63 \%$ had never used the portfolio as a result of their clinical experiences. The authors concluded that the lack of value was because the portfolio was not assessed, but rather used to stimulate discussion with tutors relating to progress through the course, and goals for future employment. Although only one study, this throws into question whether the three elements required in a portfolio as described by Zubizarretta (2008) actually do produce deep learning. ${ }^{21}$

\section{Limitations.}

There are several limitations to this study. Not all of the literature relating to student portfolios was reviewed; as part of the doctoral study, a conscious decision was taken to exclude any papers specifically exploring portfolios as an assessment method, or studies comparing different types of portfolios, e.g. paper vs. e-portfolios. This means that some data 
relating to students' attitudes to or perceptions of portfolios may have been missed. Only one author reviewed and analysed the literature, and therefore this could have introduced bias to the process. Lack of detail within the studies regarding all of the elements considered - aims, purpose, structure, standardisation, content - means that conclusions have been drawn with some missing information.

\section{Conclusion.}

Portfolios are widely used within higher education, and particularly in pre-registration education of health professionals. There are several benefits suggested to their use, including encouragement of reflection, providing links between academic knowledge and clinical practice, promoting critical thinking, and development of independent and self-directed learners. One model of portfolio learning suggests evidence collection, reflection and collaboration with more experienced colleagues are all required for students to achieve deep learning through the use of a portfolio. The evidence from this review suggests that factors such as portfolio aims, purpose, structure, format and content have little influence on students' perceptions of or attitudes to the use of a portfolio as a means of learning, with responses within studies being mainly negative in relation to the value of the portfolio, the time required to undertake portfolio work, and the guidance given related to this work. Students generally reported positively in terms of development of reflective skills and being more prepared for future professional CPD requirements as a result of using a portfolio. While the evidence is limited regarding the three requirements of evidence collection, reflection and collaboration, ${ }^{21}$ it is proposed that even the inclusion of all three of these elements does not appear to improve students’ generally negative views on portfolios. Despite the positive responses with regard development of reflective skills as part of using their portfolios, students did not see the benefit of this, and further research should explore 
whether this is because they do not value reflection, or whether they do not understand the purpose of it, in relation to their practice. It is also evident that portfolios continue to be used by educators, despite the negative attitudes from students regarding their use, and further exploration is required to determine how or if it is possible to enable students to engage in portfolio learning, in order to achieve the benefits that are suggested within the literature.

\section{Key Messages.}

\section{What is already known on this topic.}

Portfolios are widely used within higher education, and particularly within the education of health professionals. There is wide variety within these portfolios, in terms of aims, purpose, structure, format, content, and inclusion in assessment, across and within the disciplines. Despite large volumes of literature evaluating the use of portfolios as learning tools, there has been relatively little discussion regarding the factors influencing student engagement and recognition of value of portfolio learning.

\section{What this study adds.}

This study showed that there does not appear to be a clear link between the aims of a portfolio, its structure or content, and students' attitudes to or perceptions of portfolios as a means of learning. Regardless of aims, structure, content, students generally feel the portfolio assists in development of reflective skills and prepares them for the future CPD requirements. However, there appears to be interplay between a number of factors, which impact on the value students place on their portfolios, such as the role of assessment, the guidance and support provided, and the time implications of maintaining and developing their portfolios. Educators need to consider these factors when deciding how to design portfolios within their programmes of study, and should clearly articulate the purpose of this method of learning to students, in order to try to improve the value given to portfolio use. 
1. Jarvinen, A., Kohonen, V. Promoting professional development in higher education through portfolio assessment. Assessment and Evaluation in Higher Education, 1995; 20(1), 25-36.

2. Scott, D. Assessment in the arts: portfolio performance. Childhood Education, 1992; 69(2), 96-99.

3. Bedford, H., Phillips, T., Robinson, J., Schostak, J. Assessing competencies in nursing and midwifery education. 1993; London: English National Board for Nursing, Midwifery and Health Visiting.

4. Usherwood, T., Hannay, D. Profile based assessment of student project reports. Medical Teacher, 1992; 14, 189-196.

5. Cross, V. The professional development diary: A case study of one cohort of physiotherapy students. Physiotherapy (London), 1997; 83(7), 375.

6. Williams, J. The clinical notebook: Using student portfolios to enhance clinical teaching learning. Journal of Nursing Education, 2001; 40(3), 135-7.

7. Gathercoal, P., Love, D., Bryde, B., McKean, G. On implementing web-based electronic portfolios. Educause Quarterly, 2002; 25, 29-37.

8. Cottrell, R. R., Girvan, J. T., McKenzie, J. F. Principles and foundation of health promotion and education ( $2^{\text {nd }}$ Edn) 1992; San Francisco: Benjamin Cummings.

9. Slusarchuk, R. Progressing through lifelong learning: a personal view of the basic features of progress files. Adult learning, 1998; 9 (6).

10. Andre, K. E-portfolios for the aspiring professional. Collegian, 2010; 17, 119-124.

11. Baume, D. Supporting Portfolio Development; Continuing Professional Development Series No. 3. 2003; York: Learning and Teaching Support Network (LTSN). 
12. Gaberson, K., Oermann, M. H. Clinical teaching strategies in nursing education. 1999; New York: Springer.

13. Wenzel, L., Briggs, K., Puryear, B. Portfolio: authentic assessment in the age of the curriculum revolution. Journal of Nursing Education, 1998; 37, 208-212.

14. Grant, G. E., Huebner, T. A. The portfolio question: a powerful synthesis of the personal and professionals. Teacher Education Quarterly, 1998; 25, 33-43

15. Oermann, M.H. Developing a professional portfolio in nursing. Orthopaedic Nursing, 2002; 21(2), 73-78.

16. Swingonski, M., Ward, K., Mama, R. S., Rodgers, J., Belicose, R. An agenda for the future: student portfolios in social work education. Social Work Education, 2006; 25(8), 812-823.

17. Kostrzewski, A. J., Dhillon, S., Goodsman, D., Taylor, K. M. G. The impact of portfolios on health professionals’ practice: a literature review. International Journal of Pharmacy Practice, 2008; 16(6), 339-345.

18. Klenowski, V., Askew, S., Carnell, E. Portfolios for learning, assessment and professional development in higher education. Assessment and Evaluation in Higher Education, 2006; 31(3), 267-287.

19. Azer, S.A. Use of portfolios by medical students: significance of critical thinking. Kaohsiung Journal of Medical Science, 2008; 24(7), 361-366.

20. Paulson, F. L., Paulson, P. R., Meyer, C. A. What makes a portfolio a portfolio? Educational Leader. 1991; Accessed on 20.10.2015. Available at http://web.stanford.edu/dept/SUSE/projects/ireport/articles/eportfolio/what $\% 20$ makes\%20a\%20portfolio\%20a\%20portfolio.pdf 
21. Zubizarretta, J. The Learning portfolio: a powerful idea for significant learning. Ideas Paper \#44. 2008; Accessed on 12/11/15, Available at: http://ideaedu.org/wpcontent/uploads/2014/11/IDEA_Paper_44.pdf

22. Bulman, C., Schulz, S. Reflective practice in nursing, $3^{\text {rd }}$ Edition. 2004; Oxford: Blackwell publishing.

23. Driscoll, J., Teh, B. The potential of reflective practice to develop individual orthopaedic nurse practitioners and their practice. Journal of Orthopaedic Nursing, 2001; 5(2), 95-103.

24. Driessen, E. W. Are learning portfolios worth the effort? Yes. British Medical Journal, 2008; 337, p a513.

25. Bryman, A., Burgess, R. G. Analysing Qualitative Data. 1994; London: Routledge.

26. Urish, C. K. Meaning ascribed to learning portfolios of graduate level rehabilitation counseling students. University of Iowa). 2005; 231 p. (UMI Order AAI3202969.)

27. Mubuuke, A. G., Kiguli-Malwadde, E., Kiguli, S., Businge, F. A student portfolio: The golden key to reflective, experiential, and evidence-based learning. Journal of Medical Imaging and Radiation Sciences, 2010; 41(2), 72-78.

28. Elango, S., Jutti, R. C., Lee, L. K. Portfolio as a learning tool: Students’ perspective. Annals of the Academy of Medicine Singapore, 2005; 34(8), 511-514.

29. Finlay, I. G., Maughan, T. S., Webster, D. J. A randomized controlled study of portfolio learning in undergraduate cancer education. Medical Education, 1998; 32(2), 172-176.

30. Fung, M. F., Walker, M., Fung, K. F., Temple, L., Lajole, F., Bellemare, G., et al. An internet-based learning portfolio in resident education: The KOALA multicenter programme. Medical Education, 2000; 34(6), 474-479. 
31. Graham, G., Megarry, B. The Social Work Portfolio: An aid to integrated learning and reflection in social care training. Social Work Education, 2005; 24(7), 769-780.

32. Murphy, J. E., Airey, T. C., Bisso, A. M., Slack, M. K. Student evaluations of the portfolio process. American Journal of Pharmaceutical Education, 2011; 75(7), 1-132.

33. Advani, A., Ashworth, L., Barnett, C., Miller, S. W., Sachdeva, V. Assessment of pharmacy students’ attitudes regarding professional development portfolios: Before and after practitioners’ roundtable discussion. Currents in Pharmacy Teaching and Learning, 2014; 6(3), 373-379.

34. Austin, C., Braidman, I. Support for portfolio in the initial years of the undergraduate medical school curriculum: What do the tutors think? Medical Teacher, 2008; 30(3), 265-271.

35. Dolan, G., Fairbairn, G., Harris, S. Is our student portfolio valued? Nurse Education Today, 2004; 24(1), 4-13.

36. Bradley, R., Schofield, S. The undergraduate medical radiation science students' perception of using the e-portfolio in their clinical practicum. Journal of Medical Imaging and Radiation Sciences, 2014; 45(3), 230-243.

37. Alexander, J. G., Craft, S. W., Baldwin, M. S., Beers, G. W., McDaniel, G. S. The nursing portfolio: A reflection of a professional. Journal of Continuing Education in Nursing, 2002; 33(2), 55-59.

38. Kalet, A. L., Sanger, J., Chase, J., Keller, A., Schwartz, M. D., Fishman, M. L., Garfall, A. L., Kitay, A. Promoting professionalism through an online professional development portfolio: Successes, joys, and frustrations. Academic Medicine: Journal of the Association of American Medical Colleges, 2007; 82(11), 1065-1072. 
39. Altahawi, F., Sisk, B., Poloskey, S., Hicks, C., Dannefer, E. F. Student perspectives on assessment: Experience in a competency-based portfolio system. Medical Teacher, 2012; 34(3), 221-225

40. Gordon, J. Assessing students' personal and professional development using portfolios and interviews. Medical Education, 2003; 37(4), 335-340.

41. Heijne, A., Nordgren, B., Hagströmer, M., Fridén, C. Assessment by portfolio in a physiotherapy programme. Advances in Physiotherapy, 2012; 14(1), 38-46.

42. Lonka, K., Slotte, V., Halttunen, M., Kurki, T., Tiitinen, A., Vaara, L., et al. Portfolios as a learning tool in obstetrics and gynaecology undergraduate training. Medical Education, 2001; 35(12), 1125-1130.

43. Thompson, R., Farrow, T. The workbook portfolio: Facilitating undergraduate student learning in the mental health clinical area. Nursing Praxis in New Zealand Inc, 1999; 14(2), 21-30.

44. Nairn, S., O'Brien, E., Traynor, V., Williams, G., Chapple, M., \& Johnson, S. Student nurses' knowledge, skills and attitudes towards the use of portfolios in a school of nursing. Journal of Clinical Nursing, 2006; 15(12), 1509-1520.

45. Driessen, E. W., Jan van Tartwijk, Vermunt, J. D., van der Vleuten., C. P. M. Use of portfolios in early undergraduate medical training. Medical Teacher, 2003; 25(1), 1823.

46. Stuart, C. C. The use of a portfolio of clinical evidence to influence student learning in midwifery education. Birth Issues, 2004; 13(4), 121-127.

47. Gomez, S. S., Ostos, E. M. C., Solano, J. M. M., Salado, T. F. H. An electronic portfolio for quantitative assessment of surgical skills in undergraduate medical education. Medical Education, 2013; 13(65), 1-9. 
48. Funk, K. P. Student experiences of learning portfolios in Occupational Therapy education. Occupational Therapy in Health Care, 2007; 21(1-2), 175.

49. Haffling, A., Beckman, A., Pahlmblad, A., Edgren, G. Students' reflections in a portfolio pilot: Highlighting professional issues. Medical Teacher, 2010; 32(12), E532.

50. Alvarez, A. R., Moxley, D. P. The student portfolio in Social Work Education. Journal of Teaching in Social Work. 2004; 24. 87-103.

51. Grant, A., Vermunt, J., Kinnersley, P., Houston, H. Exploring students' perceptions on the use of significant event analysis, as part of a portfolio assessment process in general practice, as a tool for learning how to use reflection in learning. BMC Medical Education, 2007; 7(1), 5.

52. Royal College of Nursing. Continuing professional development for nurses working in the UK. 2014. London, Royal College of Nursing.

53. Health and Care Professions Council. CPD and your registration. 2014. London, HCPC.

54. General Medical Council. The good medical practice framework for appraisal and revalidation. 2013. Manchester, GMC.

55. American Physical Therapy Association. Professional Development, Lifelong Learning and Continuing Competence in Physical Therapy. 2012. Accessed on 25.11.15, available at http://www.apta.org/search.aspx?q=continuing professional development

56. Nursing and Midwifery Board of Australia. Continuing Professional Development registration standard. 2010. Melbourne, NMBA. 
Appendix 1 - Influence of Aims/Purpose of Portfolio on Student Responses to Themes

476 (number $=$ the number of studies in which students had this response)

\begin{tabular}{|c|c|c|c|c|c|c|c|c|c|c|c|c|}
\hline \multirow[t]{2}{*}{$\begin{array}{l}\text { AIMS OR } \\
\text { PURPOSE OF } \\
\text { PORTFOLIOS } \\
\text { THEMES OF } \\
\text { STUDENT } \\
\text { RESPONSES }\end{array}$} & \multicolumn{2}{|c|}{ 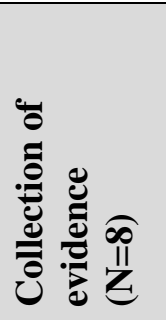 } & \multicolumn{2}{|c|}{ 氖 } & \multicolumn{2}{|c|}{ 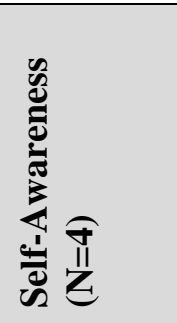 } & \multicolumn{2}{|c|}{ 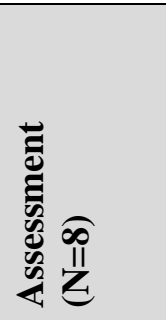 } & \multicolumn{2}{|c|}{ 泀 } & \multicolumn{2}{|c|}{ 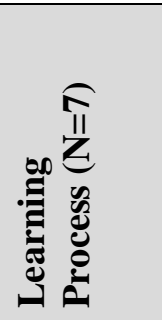 } \\
\hline & 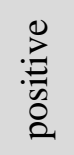 & 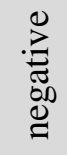 & 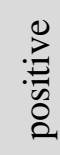 & 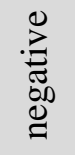 & 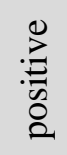 & 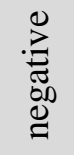 & : & 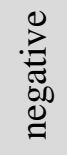 & 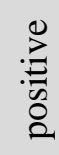 & 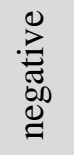 & $:$ & 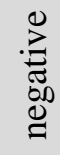 \\
\hline Learning & 1 & 1 & 1 & 1 & & & 3 & 2 & & 1 & 2 & 2 \\
\hline $\begin{array}{l}\text { Theory to } \\
\text { Practice Link }\end{array}$ & & & & & & 1 & & 1 & 1 & 1 & & 1 \\
\hline $\begin{array}{l}\text { Learning from } \\
\text { Practice }\end{array}$ & & & 1 & & & & 1 & 1 & & & & \\
\hline Self-awareness & & & 1 & & & 1 & 2 & 1 & & 1 & & 1 \\
\hline $\begin{array}{l}\text { Reflective } \\
\text { skills }\end{array}$ & 1 & & 2 & & 2 & & 2 & & 2 & 1 & 2 & \\
\hline $\begin{array}{l}\text { Reflective } \\
\text { Writing }\end{array}$ & & & & & 1 & 1 & 1 & 1 & 1 & & 1 & 1 \\
\hline Thinking Skills & & & 1 & & & & 2 & & 1 & & & \\
\hline $\begin{array}{l}\text { Skill } \\
\text { Development }\end{array}$ & & & & & & & 1 & 1 & 1 & & 1 & \\
\hline $\begin{array}{l}\text { Professional } \\
\text { Skills and } \\
\text { Attributes } \\
\end{array}$ & & & & & & 1 & 1 & & & 1 & & 1 \\
\hline $\begin{array}{l}\text { Responsibility } \\
\text { for own } \\
\text { development }\end{array}$ & & & 1 & & & & 1 & & & & & \\
\hline $\begin{array}{l}\text { Lifelong } \\
\text { Learning }\end{array}$ & 1 & & 1 & & & & & & & & 1 & \\
\hline $\begin{array}{l}\text { Influence on } \\
\text { Practice }\end{array}$ & & 1 & & 2 & & & & 1 & & 1 & & 1 \\
\hline $\begin{array}{l}\text { Emotional } \\
\text { aspects, stress, } \\
\text { anxiety }\end{array}$ & & & 1 & 1 & & 1 & 2 & 2 & & 1 & 1 & 2 \\
\hline Honesty & & & & & & & & 1 & & & & \\
\hline $\begin{array}{l}\text { Guidance } \\
\text { given }\end{array}$ & & & & 1 & & & & 2 & & & & 1 \\
\hline Time taken & 1 & & & & & & & 3 & & 2 & & 2 \\
\hline $\begin{array}{l}\text { Value of } \\
\text { portfolio }\end{array}$ & & 1 & & 2 & & & & 2 & & 2 & & 3 \\
\hline $\begin{array}{l}\text { Assessment by } \\
\text { portfolio }\end{array}$ & & 1 & 1 & & & 1 & 3 & 3 & & 2 & & 2 \\
\hline $\begin{array}{l}\text { Preparation } \\
\text { for the future }\end{array}$ & 2 & & 2 & & 1 & & 1 & & 3 & & 3 & \\
\hline
\end{tabular}


Appendix 2 - Influence of Level of Standardisation of Portfolio on Student Responses to

479 Themes (number $=$ number of studies in which students had response)

\begin{tabular}{|c|c|c|c|c|c|c|}
\hline $\begin{array}{l}\text { STANDARDISATION OF } \\
\text { PORTFOLIO } \\
\text { THEMES OF STUDENT } \\
\text { RESPONSES }\end{array}$ & 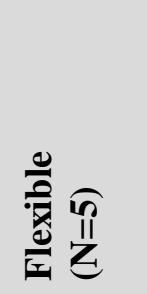 & & • & & 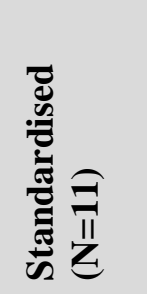 & \\
\hline & positive & negative & positive & negative & positive & negative \\
\hline Learning & 3 & 2 & 1 & 3 & & 3 \\
\hline Theory to Practice Link & & & & & 1 & \\
\hline Learning from Practice & & & 1 & & & \\
\hline Self-awareness & 2 & 1 & 1 & & & \\
\hline Reflective skills & 1 & & 2 & & 3 & \\
\hline Reflective Writing & & & & & 1 & 1 \\
\hline Thinking Skills & 1 & 1 & 2 & & 2 & \\
\hline Skill Development & & & & & & 1 \\
\hline Professional Skills and Attributes & 1 & & & & & \\
\hline $\begin{array}{l}\text { Responsibility for own } \\
\text { development }\end{array}$ & & & 2 & & & \\
\hline Lifelong Learning & & & 2 & & & \\
\hline Influence on Practice & 1 & & & & & \\
\hline Emotional aspects, stress, anxiety & 2 & 2 & 1 & 1 & & \\
\hline Honesty & & & & & & 1 \\
\hline Guidance given & 1 & 2 & & 1 & & 3 \\
\hline Time taken & & & & 1 & & 3 \\
\hline Value of portfolio & & 2 & 1 & 1 & 1 & 4 \\
\hline Assessment by portfolio & 1 & & 1 & 1 & 1 & \\
\hline Preparation for the future & & & 1 & & 3 & \\
\hline
\end{tabular}

